\title{
"The role of insurance in the management of disaster risk: the case of the Italian cathedrals"
}

Donatella Porrini iD http://orcid.org/0000-0003-0305-5456

AUTHORS

R http://www.researcherid.com/rid/N-6000-2015

Francesco De Masi iD https://orcid.org/0000-0002-0712-663X

R http://www.researcherid.com/rid/B-4307-2019

ARTICLE INFO

Donatella Porrini and Francesco De Masi (2019). The role of insurance in the management of disaster risk: the case of the Italian cathedrals. Insurance Markets and Companies, 10(1), 9-25. doi:10.21511/ins.10(1).2019.02

DOI http://dx.doi.org/10.21511/ins.10(1).2019.02

RELEASED ON Saturday, 23 March 2019

RECEIVED ON

Tuesday, 29 January 2019

ACCEPTED ON

Tuesday, 12 March 2019

\section{$((\mathrm{cc})$ EY}

LICENSE

This work is licensed under a Creative Commons Attribution 4.0 International License

JOURNAL

"Insurance Markets and Companies"

ISSN PRINT 2616-3551

ISSN ONLINE 2522-9591

PUBLISHER LLC “Consulting Publishing Company "Business Perspectives"

FOUNDER LLC "Consulting Publishing Company "Business Perspectives"

NUMBER OF REFERENCES

27

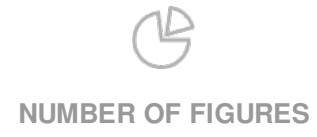

4
NUMBER OF TABLES

4

(C) The author(s) 2023. This publication is an open access article. 


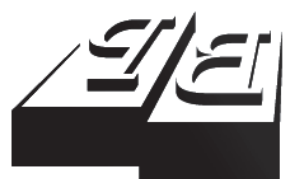

BUSINESS PERSPECTIVES

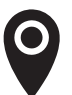

LLC "CPC "Business Perspectives" Hryhorii Skovoroda lane, 10, Sumy, 40022, Ukraine

www.businessperspectives.org

Received on: $23^{\text {rd }}$ of January, 2019 Accepted on: $12^{\text {th }}$ of March, 2019

(C) Donatella Porrini, Francesco De Masi, 2019

Donatella Porrini, Associate Professor, Dipartimento di Scienze dell'Economia, Università del Salento, Italy.

Francesco De Masi, PhD Student, Dipartimento di Scienze dell'Economia, Università del Salento, Italy.

\title{
THE ROLE OF INSURANCE IN THE MANAGEMENT OF DISASTER RISK: THE CASE OF THE ITALIAN CATHEDRALS
}

\begin{abstract}
The aim of this article is to analyze the role of insurance for the coverage of damages deriving from natural disasters, focusing on the specific case of the Italian cathedrals. In this sense, a survey was conducted among the Italian Dioceses asking them to complete a questionnaire, through which the data useful for the analysis of the spread of insurance contracts and for other qualitative and quantitative elements linked to the decisional process of being insured were collected. The achieved coverage is equal to $29.02 \%$ of the Italian Dioceses, corresponding to 65 answers of a total of 224 contacts. In particular, the questionnaires investigate insurance presence, perception and awareness, willingness to pay and future prospects. An in-depth analysis about all the data deriving from the survey is provided, trying to compare some results and finally some considerations are presented on future research perspectives. What emerges is in some aspects surprising, because it allows to identify a significant financial culture and knowledge of the importance covered by insurance in the governance of disaster risk: for $62 \%$ of the cases analyzed, they have already underwritten this type of contract.
\end{abstract}

\section{Keywords}

\section{JEL Classification} cultural heritage, risk management, cathedrals, insurance, survey

\section{INTRODUCTION}

Natural disasters together with global warming, industrial activities and terrorism, are causing increasing numbers of catastrophes, leading to higher probability of damage to historical, cultural and artistic heritage. As we have seen from the recent earthquake that hit Central Italy ${ }^{1}$, a catastrophic phenomenon can cause not only loss of human lives, but also damage to ancient churches.

According to a recent report published by ANIA (2017), "the catastrophic events of August 2016 in the Center of Italy have highlighted, once again, how vulnerable the Italian territory is and to what extent the historical buildings in Italy are incapable of withstanding earthquakes, even ones that are not particularly severe. Based on the estimates of the Department of Civil Protection, the earthquakes of the summer 2016 caused damage for over $€ 23.5$ billion, of which $€ 12.9$ billion for damages to private dwellings (the estimate includes direct damage, both public and private - namely the destruction of buildings, infrastructure, crops

This is an Open Access article, distributed under the terms of the Creative Commons Attribution 4.0 International license, which permits unrestricted re-use, distribution, and reproduction in any medium, provided the original work is properly cited.

On August 24, 2016, a magnitude 6.2 earthquake hit the Apennine Mountains in Central Italy, devastating the small towns of Amatrice, Accumoli and Pescara del Tronto. On October 26, two aftershocks of magnitude 5.5 and 6.1 hit Visso, north of Amatrice. On October 30, a magnitude 6.6 earthquake struck Norcia, situated between Amatrice and Visso. This last quake was the most powerful to hit Italy since 1980, with its tremor felt in most of the country. Overall, 299 lives were lost. 
and damage to businesses and enterprises, cultural heritage, power networks, gas and water distribution systems - and eligible costs, borne by the state in response to the emergency)" (pp. 181-182).

Therefore, it is more necessary than ever to provide for risk management strategies to deal with the effects and consequences of future disasters. And in this contribution, we are going to investigate the role the insurance sector could play, both supplying policies covering damage and proactively stimulating prevention behavior related to their customers.

Our intention is to analyze the spread of insurance for the coverage of damages deriving from natural disasters and the variables that may affect the decisional process of underwriting or not an insurance contract. To this extent, we have conducted a nationwide survey addressed to all the Dioceses along the Italian territory, asking questions that allow us to focus on both qualitative and quantitative elements. In particular, we will study three main aspects: insurance presence, perception and awareness, willingness to pay and future prospects.

The starting point of our research is represented by section 1 in which we consider the insurance relevance in this field, underling how an insurance system can play a direct role by providing coverage for the consequences of extreme events.

Section 2 presents a literary review. Section 3 is centered on the empirical analysis. It describes the questionnaire structure, identifying three main categories, as previously indicated. These categories are used in order to illustrate questions and answers. Section 4 is based on the results analysis. We provide an in-depth analysis about all the data deriving from the survey, trying to compare some results and finally some considerations are presented on future research perspectives, using the questionnaire methodology as the articles in the references.

\section{THE ROLE OF INSURANCE IN THE GOVERNANCE OF RISK}

It is a fact that, as far as Italy is concerned, the entire country is exposed to one form of major natural hazard or another, including earthquakes, volcanic eruptions, tsunamis, floods, landslides and debris flows. As an example, as far as the seismic risk is concerned, the historical analysis confirms this consideration: only in the last 150 years, a seismic disaster occurred on average every $4-5$ years; in the same period, more than 2,800 landslides and a particular elevated number of floods occurred in the country (Guidoboni \& Valensise, 2013).

In recent years, seismic and hydrological disasters have claimed a number of lives and generated large economic losses. Those losses mount when adding the costs of damage to structures of cultural heritage and historical significance, of which there are many in Italy.
The National Department for Civil Protection in Italy coordinates the emergency response to natural catastrophes and other disasters and has often been regarded as an example of best practice in the world. Italy's overall natural hazard risk management framework is likewise rigorous, providing comprehensive guidelines to reduce exposure and vulnerability to disaster risk. This framework has evolved over a number of years, with the many disasters that have occurred yielding new learnings, often in tragic circumstances (OECD, 2010).

To date, most losses arising from natural disaster events have been covered by the Italian government on a post-event funding basis, such as by increasing taxes or re-allocating funds from other state programs.

In the past, public disaster relief was often followed by new tax burdens (additional income tax or VAT tax) or parafiscal taxes (increase in the excise tax on petrol) that applied to all citizens. In addition, these taxes were not eliminat- 
ed once the repair or reconstruction work was completed $^{2}$.

With the objective of reducing the high tax pressure on citizens, the Italian state is beginning to realize that the public sector cannot rely on the general public to bear the cost of rebuilding areas that are struck by natural disasters, for example, through excise taxes or the ex-post introduction of new ad hoc taxes.

Other issues encountered in the current Italian system essentially relate to the nature of ex-post state intervention, with uncertainties about the size and actual payment of the compensation, excessively long time required to obtain compensation, lack of transparency with regard to payments and possible allocation inefficiencies, low incentives to invest in prevention (Gizzi et al., 2016).

Given the problems related to the current system, increasingly, the debate concerns the use of insurance recognized as an integral component of natural catastrophe risk management systems. Italy has a long tradition in this field: the world's first known insurance contract, dating to 1347 , was found in Genoa (Nelli, 1972). Yet this early thinking has not followed through in the realm of natural catastrophe risk management. In spite of its high susceptibility to disasters, insurance penetration for natural catastrophe risk in Italy is among the lowest of the industrialized countries (De Masi \& Porrini, 2018).

From a governance perspective, insurance can play an important role in reducing the negative consequences of an adverse event after its occurrence. One of the key objectives of insurance is to facilitate damage recovery via financial compensation. Moreover, insurance can assume an important function in shouldering the financial risk from hazards by distributing the financial burden over time and space (Porrini, 2011).

Insurance is a mechanism where risks or parts of a risk are transferred from one party (the insured) to another (the insurer) in exchange for a payment (the premium). At its most basic, insurance therefore constitutes a transaction between two indi- vidual entities. Beyond the individual transaction, insurance has a distinctively social dimension. This is because insurers aggregate individual risks into collective risk pools (Hoy, 1982; Abraham, 1985). The establishment of such pools enables insurers to distribute individual risks over time and space, and draw on, among other sources such as reinsurance and investment income, the collective premium revenue to provide compensation to groups of insurance holders affected by a disaster.

Insurance companies can be seen as particularly well suited for taking on this role efficiently as a result of its financial reserves and its expertise in risk assessment. Risk assessment helps insurers to calculate their total and annual average loss exposure. This in turn enables insurers to generate adequate reserves from collecting premiums across time and space, through investing premium income in capital markets, and eventually drawing on reinsurance to provide financial compensation swiftly after a natural disaster occurs (Priest, 1996; Harrington, 2000).

One way of addressing the financial risks to insurers is their capability of reducing risk even before the adverse event occurs: this is a key governance objective associated with involving private insurers.

Insurance companies are able to provide economic incentives for risk avoiding and mitigating behavior and to mobilize financial resources at short notice and may offer more efficient and sustainable alternatives to a government's regulatory and financial efforts. It is important to bear in mind that insurance, while being in theory able to contribute to both natural risk management before and after events, complements and reinforces a wide range of measures that are undertaken mostly by public authorities to reduce risks.

Porrini and Schwarze (2014) argue that governments could benefit significantly from using an insurance instrument capable not only of covering damage, but also of providing an incentive for risk reduction behaviors.

This contribution examines the case of the churches, which are particular infrastructures with tradition and great value.

2 One of the many examples is the excise taxes on petrol that dates back to 1963, following the Vajont disaster. 
The assessment of their value is subject to special factors, because these are often unique and of high immaterial value: emotional, historical, artistic-aesthetic and obviously religious.

Churches include a set of recognized assets that reflect the historical, socioeconomic, political, scientific, artistic and educational importance of something that has been created as a visible landmark by our ancestors. It is a historical social asset that cannot be substituted in case of loss or damage and as such differs from normal economic goods. In fact, there is essentially no market for such goods, since they cannot be replaced or reproduced.

The economic value of churches includes the amount of welfare that they generate for society. Total economic value is defined in terms of use and non-use values. The use value is the value one gets from actually visiting and attending a certain site (direct use), as well as all the recreational facilities it provides (indirect use). The non-use value, on the other hand, is the value it creates simply from the knowledge of its existence (existence value), the possibility of having the chance to visit it in some future time (option value) and the satisfaction one has knowing that it will be a value for future generations (bequest value). One of the more fundamental components of risk management is the preservation of a society's heritage, especially its historic buildings and structures. Heritage preservation policy focuses on large public structures as symbols of local, national, or even global heritage.

This guarantee may come from preservation policy in light of the irreversibility of historic qualities of structures, because once the original landmark is lost to damage or redevelopment, the change is irreversible and authentic substitutes might not exist (Throsby, 2010).

It can be assumed that successful preservation of such a property is strongly connected with preventive measures. However, damage can occur despite the best security arrangements and natural disasters represent the greatest threat to cultural property, an immense potential danger, from which total protection is impossible. Therefore, the basic question of risk management financing also arises regarding churches.
The question as to whether a classic risk management process can be applied to cultural property protection can definitely be answered in the affirmative (Gizzi \& Porrini, 2017).

Whenever a catastrophic event happens, a relevant issue emerges for the costs of reconstruction. The importance of internalizing these kinds of costs comes from the fact that the victims ask for the reconstruction of monuments, historical buildings, and art work, because they are symbols of their community and represent the identity of a territory that cannot be abandoned. In this sense, heritage is a public good that corresponds to a set of recognized assets that reflect the historical, socioeconomic, political, scientific, artistic and educational features.

This increase in the sensitivity to risks forms the basis for long-term sustainable solutions for managing dangers by incorporating all of the available options.

With regard to handling the consequences on cultural heritage, an insurance system can play a direct role by providing coverage for the consequences of extreme events. This role was already emphasized by the Council of Europe over twenty years ago, in 1993 by Recommendation No. R(93)9. The document advises national states to make any legal effort to facilitate the coverage of the architectural heritage against losses and damage caused by disasters.

Particularly regarding financial and insurance measures:

"1. Financing disaster prevention and mitigation: adequate and quickly accessible resources should be established both for planned maintenance, upgrading and preventive work and for contingency funding in the event of a disaster, for instance by setting up national and local funds.

\section{Insurance:}

i. states should remove any legal obstacles and facilitate the insurance of buildings and objects, which comprise the architectural heritage, against loss and damage caused by disasters and against theft and arson; 
ii. all steps to encourage, support and facilitate full and appropriate insurance cover should be taken;

iii. policies should ensure that the sums insured shall represent the full cost to be incurred at the time of the loss or damage, in order to repair, restore or reinstate the buildings or objects to their condition before the disaster; using materials, workmanship and techniques according to best conservation practice. If a policy stipulates an excess or co-insurance, the insured should prove that he has the means to cover such sums out of his own funds;

iv. the buildings and objects should be inspected regularly by experts and insurers and the conditions and warranties stipulated in connection with such inspections should be binding;

v. efforts should be made to ensure full co-operation and the exchange of information and expertise between the authorities and the insurance companies" (Council of Europe, 1993, p. 3).

As a matter of fact, the insurance companies are well equipped to calculate actuarial risks and to set adequate premiums and contractual conditions, such as coverage and deductibles, and are also inclined to gear their calculations towards a long time horizon, which enables valuation of and planning for low probability-high loss events.

Prevention is obviously better than the cure, as, no matter how well reinstatement work is carried out, the loss of historic buildings is irreversible. Insurance cover is not only a fallback position, which provides compensation to owners in the event of loss or damage in order repair or reinstatement. In fact, insurance companies are motivated to take significant actions aimed at mitigating overall societal effects and increasing adaptive capacity, because these actions will reduce overall uncertainty and other barriers to insurability (Kunreuther, 1996), by reducing insurers' potential exposure to catastrophic risks in excess of their capacity, as well as the potential for property and liability claims in excess of current pricing structures.

\section{Empirical analysis}

The research here proposed is focused on the scientific analysis of the spread, in Italian Dioceses, of insurance products for the coverage of damages deriving from natural disasters.

\section{LITERATURE REVIEW}

Many papers investigate natural disasters and the way to adopt insurance for the coverage of damages.

Some of them focus on the potential value of insurance as a substitute for government regulation of safety (Ben-Shahar \& Logue, 2012), or to support decision makers in exploring ways to implement insurance solutions (Warner et al., 2013; Le Den et al., 2017).

The potential value of insurance emerges as depending very much on the penetration of insurance and this point is investigated in another branch of papers that carry out analysis on the demand for insurance. Browne and Hoyt (2000) for example conduct and empirical analysis about the influential factors in the decision to purchase flood insurance in the case of United States' National Flood Insurance Program (NFIP).

The issue of the situation of "under-insurance" and the consequent protection gap in relation to natural disasters coverage has been addressed many times in the economic literature. For example, Holzheu and Turner (2018) combined historical data and probabilistic models to estimate for 53 countries the protection gap in property risks by geography and risk type.

Other papers investigate some features of the demand of insurance using nationwide survey and questionnaires. Wang et al. (2012) investigate the social basis for establishing a disaster insurance system in China and conducted a nationwide survey to establish factors that may affect people's acceptance of homeowners' disaster insurance.

As far as cultural heritage is concerned, Chiabrando et al. (2018) focus on the way to increase resilience of cultural heritage, Graham and Spennemann 
(2007) highlight the importance of heritage preservation in natural disasters situations.

As far as we know, no paper before ours has specifically analyzed the case of penetration of insurance coverage against natural disasters in the specific case of cultural heritage represented by cathedrals.

\section{QUESTIONNAIRE STRUCTURE}

Through the construction of a data bank, we try to evaluate the relevance of the insurance instrument and the sensibility demonstrated by the different diocesan realities in Italy.

To reach this goal, we have formulated a specific questionnaire, distributed to all 224 Italian Dioceses $^{3}$, in order to evaluate both qualitative aspects and quantitative elements, trying to show the most complete picture. In particular, the aim of the questionnaire is to verify the presence of these insurance products specifically for the cathedrals, to homogenize the collected data, finding out at the same time in the cathedral the representative monument of each single diocesan reality.

Referring to what we have affirmed in the previous paragraph, the safety of the cathedrals, as liturgical and spiritual hearths of the numerous Italian Dioceses, as well as monuments of a huge artistic relevance, is extremely central in the subject that we want to deal with.

The capacity of knowing how to manage and protect such a heritage can provide an example to follow in order to safeguard all of those goods that can be damaged by natural disasters.

According to these evaluations, our research wants to increase the sensibility towards these considerations, trying to analyze in particular the spread of the insurance policies as instruments for the coverage of damages deriving from natural disasters.
The proposed questionnaire consists of eight questions, with the goal of observing and investigating the decisional process aspects that lead to the submission of insurance.

We have constituted three different categories ${ }^{4}$ :

- insurance presence;

- perception and awareness;

- willingness to pay and future prospects.

The questionnaire opens with the indication of the Diocese of affiliation. This request has allowed us to identify the geographic origin, with related considerations linked to the territory and its dimension. Thanks to this information, it has been possible to divide up and classify the answers, in order to analyze the sample structure and carry out an analysis for homogeneous classes.

In relation to the three categories above, the questionnaire is structured in the following way.

\subsection{Questions on the insurance presence}

In this subsection, we ask participants to specify if there is an insurance contract for the cathedral of the related Diocese to cover damages deriving from natural disasters. Based on the answer given, the questionnaire has two alternative questions.

In particular, if the answer to the first question is positive, indicating the presence of an insurance policy for the cathedral, the interviewee is to specify the event or the events covered. In this case, the respondent can choose one or more alternatives, such as earthquakes, seaquakes, floods, landslides, volcanic eruptions, meteorological events. In one column, they are asked to indicate the amount of the premium paid, in order to obtain all the elements useful to identify the underwriter profile.

In the case of negative answer to the first question, the interviewee is asked to specify the reasons for this choice. Also in this case, the respondent has at his disposal different options.

3 Here we are not considering the Diocese "Ordinariato Militare" that consists of the various chapels inside the military barracks (with a role of parish), because it doesn't include a cathedral and therefore it doesn't constitute a relevant element for our research.

4 In order to avoid confusion in the reader, we want to clarify that the categories here indicated have been realized only in a preliminary phase and used in the data analysis we are going to present. The questionnaire, indeed, does not consist of a sections partition, but a unique list of eight questions. 
In the details, the indicated motivations are:

- I don't know the insurance product;

- I don't trust the insurance companies and I am afraid of not being covered in case of a disaster;

- I don't think that it is necessary to underwrite an insurance contract, because the territory is not exposed to natural calamities;

- I do not have sufficient financial resources to underwrite an insurance contract;

- it is not necessary to underwrite an insurance contract, because I am aware of aid from the state in case of calamity;

- it is not compulsory;

- other (specify).

The choices proposed have been realized trying to include all the possible reasons that can lead to a decision for not underwriting an insurance policy. Where this goal is not met, we have decided to insert the choice "other", asking participants to specify the motivation. Thus, we have also collected qualitative data linked to the participant's sphere of decisions and the inclination towards the insurance instrument.

In this subsection, as emerges from its composition, the aim is to obtain all the information related to the position of each of the respondent Dioceses referring to the underwriting of insurance contracts. This is the starting point of the data analysis, but at the same time a point of huge importance, because it allows us to obtain results in terms of insurance spread and, as a consequence, of the sensitivity that the Dioceses have towards this policy of protection and safeguarding of their own cathedrals.

\subsection{Questions on perception and awareness}

In this subsection, we present the questions that allow us to identify more deeply the variables that influence the decisional process, trying to evaluate in particular their perception and exposition towards the risk of a catastrophic event. In other words, we want to investigate the respondent's awareness in terms of his aptitude to the underwriting of insurance contracts.

In details, the first request involves an in-depth analysis about the respondent's sensations regarding the future development of catastrophic events. We ask an opinion concerning the frequency of future natural disasters, offering four different choices: increase, decrease, unchanging, unknown.

The questionnaire proceeds with a request directly and specifically linked to risk perception. It relies on intuitive risk judgment, typically called "risk perceptions", in which experience with hazards tends to come from the news media that rather thoroughly document mishaps and threats occurring throughout the world (Slovic, 1987).

In particular, we ask them to indicate the exposition of their own territory to natural disasters. Through a question structured following the technique of the Likert scale with 5 items, the respondent can indicate a value between 1 , which stands for "low exposition", to 5 , which stands for "high exposition".

The next question is about the knowledge of catastrophic events that have damaged their region in the past and if they have benefitted from insurance coverage for the damages. The analysis of these questions allows us to document possible past experiences and any recourse to insurance solutions.

The last question of this subsection is concerned with the awareness of the importance of insurance in this sector. What we want to investigate is the knowledge of the insurance product, its relevance as a protection strategy of heritage and the connected financial culture. Also in this case, the question is structured following the technique of the Likert scale with 5 items: "In your opinion, how important is insurance as a mechanism for the coverage of damages deriving from natural disasters, from 1 (=low importance) to 5 (=high importance)?". 


\subsection{Questions on willingness to pay and future prospects}

In the third and last subsection, we investigate some elements that can positively influence the choice process, regarding the future prospective of insurance market development.

The first scenario analyzed is about tax concessions and how their introduction can facilitate the underwriting of insurance contracts. Through a question structured following the technique of the Likert scale, we ask the respondent to indicate a value between 1 and 5 , where 1 stands for very low influence in the decisional process and 5 indicates an elevated incentive to the underwriting.

The second scenario involves specific solutions that can be offered to the respondent, linked to his own territory and its natural exposition to catastrophic events, evaluating how and if it can positively influence the decision of underwriting, compared to a scenario of standard contracts for the whole national territory. Also in this case, the question follows the scheme of the Likert scale, asking to indicate a value between 1 and 5 , where 1 stands for indifference and 5 indicates a strong preference.

In the final analysis, in the eighth question, we ask the respondent to specify his willingness to pay, through a scale of six options so structured:

- from 0 to $1,000 €$;

- from 1,000 to $2,000 €$;

- from 2,000 to $3,000 €$;

- from 3,000 to $4,000 €$;

- from 4,000 to $5,000 €$;

- more than 5,000€ (please specify the amount).

The maximum amount that an individual is willing to pay for goods is a common measure, in economics, of the value of those goods (or services) to the individual (Gafni, 1998).

In particular, the answer here obtained assumes a great importance not only in relation to the willingness to pay, but also in comparison with the other information supplied filling in the questionnaire. Particularly interesting is the comparison with the Dioceses, which, although not having insurance coverage at the time, would be willing to allocate a portion of their financial resources to the underwriting of insurance contracts for the coverage of damages deriving from natural disasters.

\section{RESULTS ANALYSIS}

In this phase of study, the research shows the results obtained, following the scheme of the three categories previously indicated, analyzed at the beginning the sample composition.

As far as the sample composition is concerned, the achieved coverage is equal to $29.02 \%$ of the Italian Dioceses, corresponding to 65 answers of a total of 224 contacts. In particular, the sample composition is described, through a partition of the obtained answers in terms of geographical area.

From the collected data, a good coverage of all the national territory emerges, with percentages equal to:

- $29 \%$ for the North of Italy;

- $42 \%$ for the Center of Italy;

- $23 \%$ for the South of Italy;

- $6 \%$ for the Islands.

In detail, the numbers corresponding to these percentages are summed as follows:

- 19 answers from the North of Italy;

- 27 answers from the Center of Italy;

- 15 answers from the South of Italy;

- 4 answers from the Islands.

It emerges a majority of answers coming from the Center of Italy. This information is probably linked to the recent seismic events that occurred in these regions leading them to feel closer to the themes discussed.

In addition to this classification, we present another one based on the Dioceses' size. In this case, the Dioceses are divided in terms of number of inhabitants, according to the data published by CEI (Conferenza Episcopale Italiana) in 2014, referring to which we have found out three different classes:

- Small, with a number of inhabitants fewer or equal to 150,000 ; 
- Medium, with a number of inhabitants between 150,000 and 500,000;

- Large, with a number of inhabitants greater than 500,000 .

In detail, according to the criteria of classification above indicated, emerges a set consisting of 40.63\% small Dioceses, $46.88 \%$ medium Dioceses and $14.06 \%$ large Dioceses.

From the analysis of the collected data, it can be seen that the obtained sample consists of elements from all the categories, so that it can be considered sufficiently representative for our research. In particular, the sample is composed of elements that start from the Territorial Prelacy of Loreto, which is characterized by approximately 11,000 inhabitants, to the Milan Diocese, which, with its $5,450,312$ inhabitants, is the largest Diocese in Italy.

\subsection{Results on insurance presence}

After the preliminary analysis regarding the sample constitution, we provide an estimation of the presence, for the cathedrals of the considered Dioceses, of insurance contracts for natural disasters. In this case, it emerges that the majority of them have already underwritten this type of contract: for $62 \%$ of the cases analyzed, we have obtained a positive answer. Therefore, it is possible to deduce a great sensitivity to the theme we are dealing with and a tendency to intervene to protect the great heritage that each cathedral represents for its own Diocese.

This is a result of undoubted importance, because it allows us to affirm with a good approximation that the majority of Dioceses knows about the insurance product and has decided to underwrite the connected contracts to safeguard the cathedrals.

To understand even more the importance of the obtained result, from a comparison with the same insurance for the coverage of private houses in Italy, official statistics estimate that of the total of private homes (31,2 million according to the latest data published by ISTAT) about 610,000 are insured, that is to say $2 \%{ }^{5}$.

5 Ania Trends - Assicurazione incendio abitazioni civili, 09/2017
Therefore, the difference that we can highlight between these two realities is remarkable. This condition leads us to confirm that in the Italian Dioceses' environment there is a greater tendency to resort to insurance as a solution for the coverage of the damages deriving from natural disasters. For this reason, the existence of a developed insurance culture and a recognition of their importance in the considered sector emerges.

In this respect, the shrewdness demonstrated by the Mantua Diocese deserves a detailed study, because in 2011 it underwrote insurance contracts for its own parishes.

By questioning the traditional insurance coverage, they have adopted a trend to a cumulative policy for the Diocese in order to cover also catastrophic damages. The choice has been providential, seeing that in May 2012, over 40\% of the Dioceses churches were declared unusable by the so-called "Emilia earthquake". In the almost absence of public contributions for the reconstruction (as Mantua is in Lombardy and not in Emilia), without the insurance refunds they could not have reopened their churches ( 6 years from the earthquake, they have reopened 125 churches out of 129).

The example here reported proves the insurance relevance as an instrument for the contrast of the damages deriving from natural disasters. Compared to the inadequacy demonstrated by the public sector, this private solution, established preventatively, has produced remarkable benefits for the reconstruction activities.

Proceeding with the analysis of the spread of insurance in the national field, we now offer a detailed study about the percentages differentiated by geographic areas, in order to find out in which area they are more present.

By analyzing Figure 1, it emerges that the North of Italy is characterized by a high insurance spread, with a percentage of $79 \%$, greater than the mean referring to the collected data (62\%). The percentage from central Italy, equal to $59 \%$, is more or less in line with the calculated mean, different from the South and the Islands, where we find values 


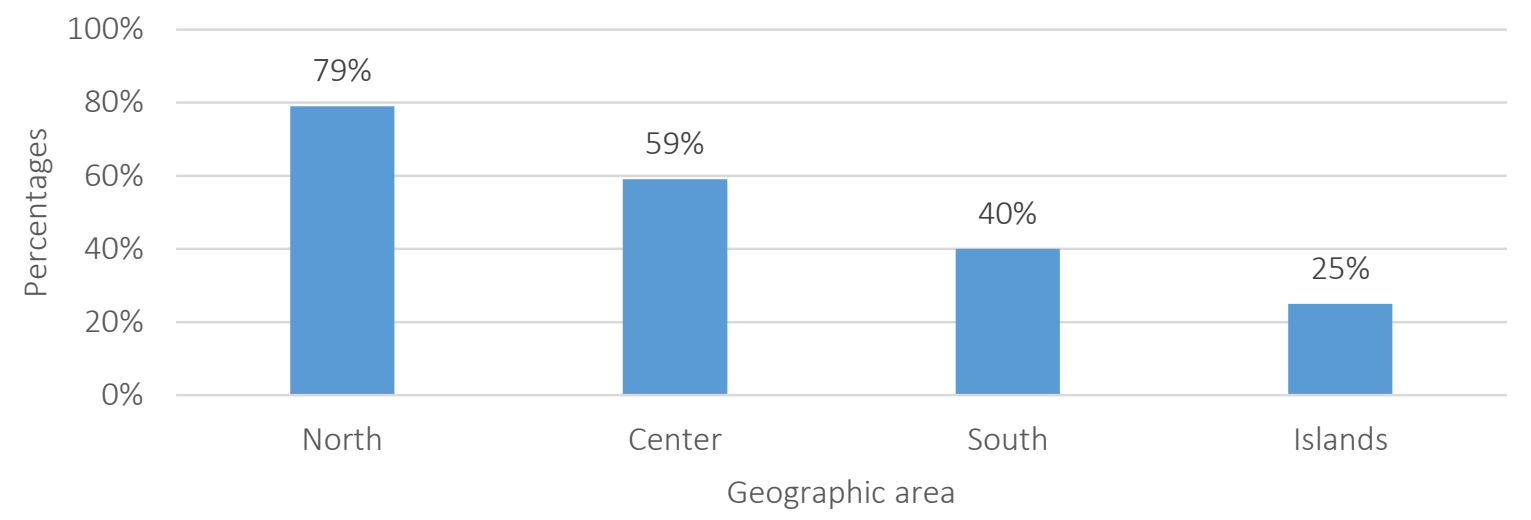

Figure 1. Insurance percentages by geographic area

under the mean, respectively, corresponding to $40 \%$ and $25 \%$.

These percentages are now compared to the map of seismic dangerousness along the national territory, with the aim of performing a first comparative analysis.
The Center of Italy is marked out by an intensive coloring, according to Figure 2, corresponding to the Apennine ridge, an area particularly exposed to seismic risk. This evaluation is unfortunately confirmed by the recent events that occurred in this region, events that caused many victims and much damage throughout the territory.

Source: Italian National Institute of Geophysics and Volcanology, April 2004.

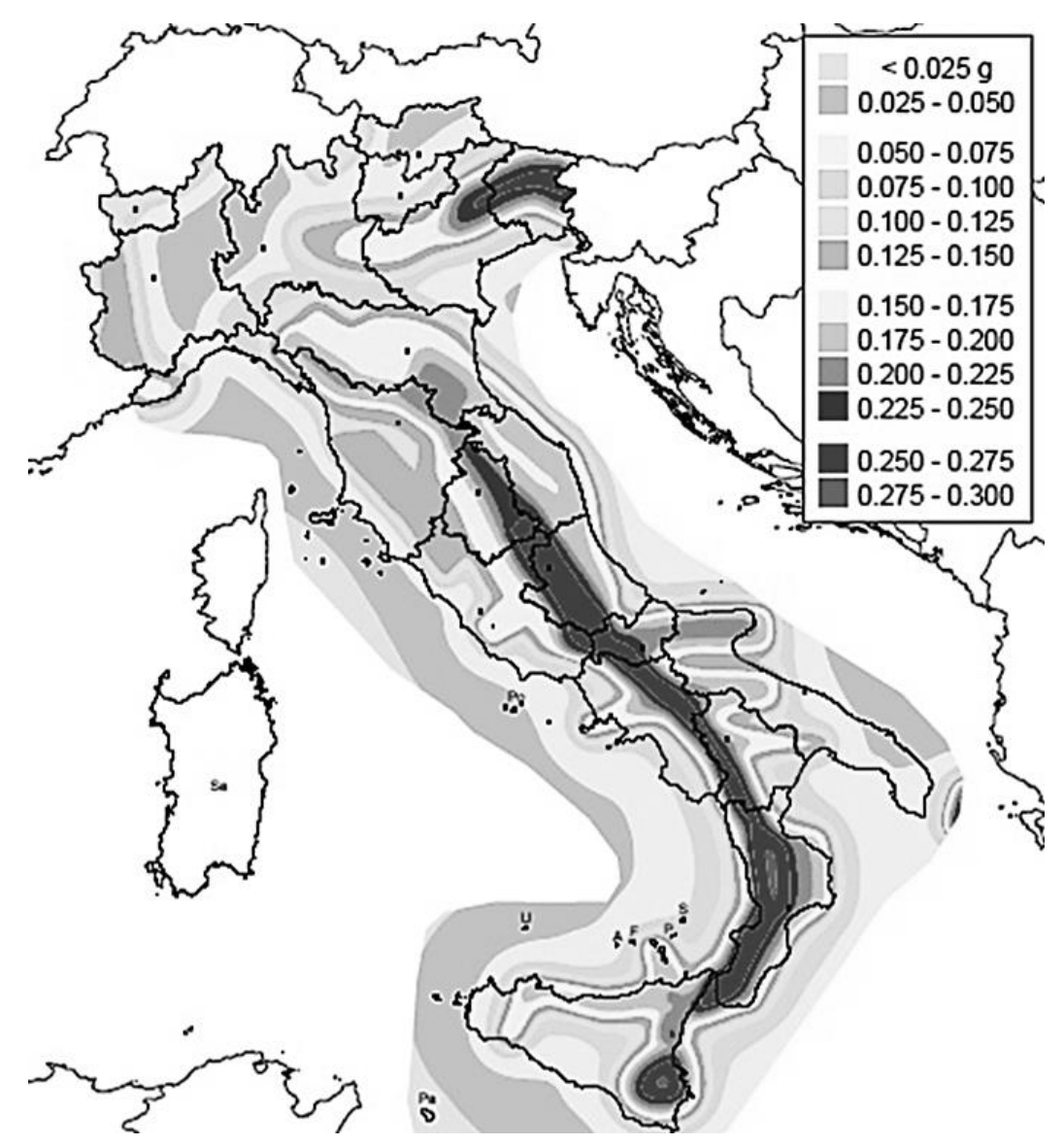

Figure 2. Map of seismic dangerousness along the national territory 


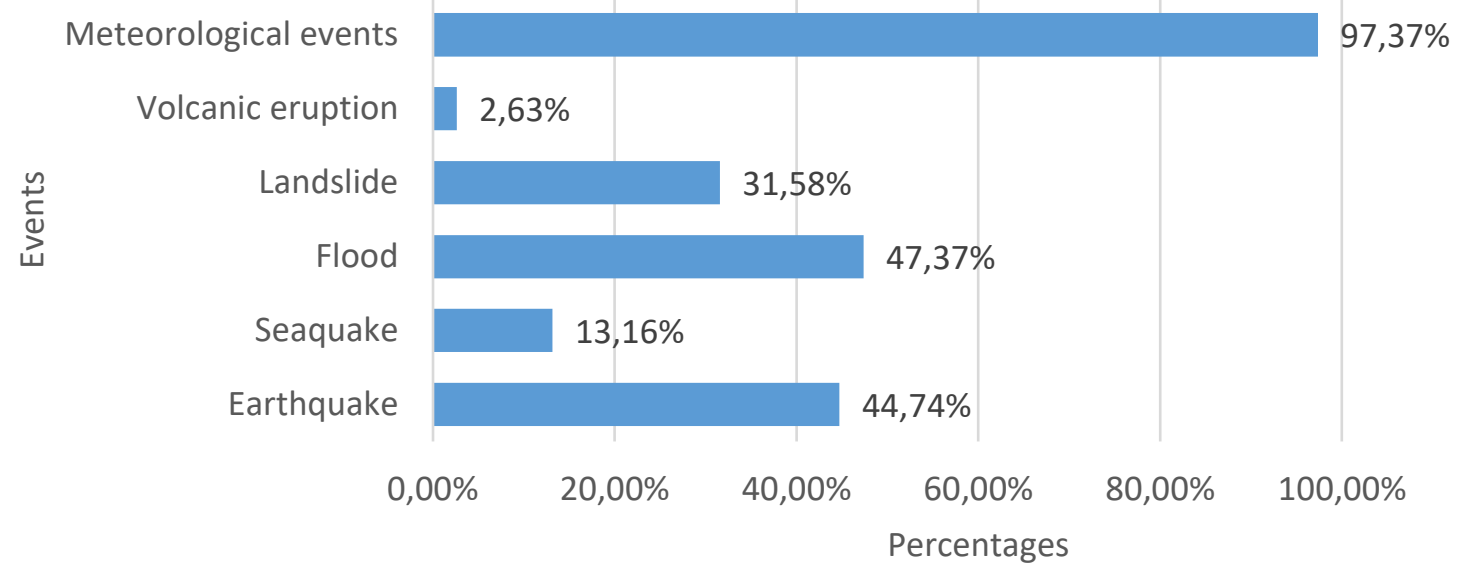

Figure 3. Insured events

Comparing this map with the collected data, we can deduce that, although the Center of Italy is the most exposed area to this risk (we are here considering only the seismic risk, leaving out the analysis of other phenomena), we do not register the highest percentage of insurance for the coverage of damages deriving from these events.

The percentage calculated consists of $59 \%$ of the cases in which they adopt insurance. Although it is not the highest value on a national scale, it is a value of undoubted importance, above all in relation to the comparison with private houses. Therefore, we underline, once again, the greater sensitivity demonstrated by the ecclesiastic world towards this kind of protection of their historic-artistic-religious heritage.

Taking into account the affirmative answers, heterogeneity of the data linked to the events towards which the Dioceses have decided to be insured emerges. In particular, we can find some categories of preeminent events, summed up as follows.

From Figure 3, we can see that the meteorological events are the set of events against which the Italian Dioceses have decided to be insured to a large extent (97.37\%). Floods and earthquakes present percentages equal to $47.37 \%$ and $44.74 \%$, while the other events are considered with less relevance.

Particularly interesting is the value obtained for meteorological events, because from the data it can be seen that they represent the main perceived adversity, with the consequent request for an insurance contract that can coverage eventual damage deriving from them. It comes out that for $42.11 \%$ of the cases the respondents have decided to be insured only in the case of these events, while for the remaining $57.89 \%$ meteorological events are chosen in association with other events.

The main choices made by the interviewed Dioceses are:

- earthquake/flood/landslide/meteorological events $15.79 \%$;

- $\quad$ flood/meteorological events $7.89 \%$;

- seaquake/flood/landslide/meteorological events $7.89 \%$;

- earthquake/meteorological events $7.89 \%$.

These values in their complexity reach a percentage of $39.46 \%$ of the cases, which, if added to

Table 1. Paid premiums

Source: Authors' own results.

\begin{tabular}{l|c|c|c:c|c}
\multicolumn{1}{c}{ Classes } & $\mathbf{1}, \mathbf{0 0 0 €}$ & $\mathbf{1 , 0 0 0 - 2 , 0 0 0 €}$ & $\mathbf{2 , 0 0 0 - 3 , 0 0 0 €}$ & $\mathbf{3 , 0 0 0 - 4 , 0 0 0 €}$ & $\mathbf{>} \mathbf{4 , 0 0 0 €}$ \\
\hline Percentages & $24 \%$ & $16 \%$ & $16 \%$ & $24 \%$ & $20 \%$ \\
\hline
\end{tabular}


the percentage referring only to meteorological events $(42.11 \%)$, allows us to obtain a percentage of $81.57 \%$; that is to say the majority of the collected data.

Table 1 offers the data linked to the premiums paid by the Dioceses, with the subdivision in classes of values and correspondent percentages of the insured. What becomes apparent is that the calculated percentages, presented in the categories above indicated, are similar to each other. At any rate, we have to underline that all the premiums are different because of a series of factors, such as the insured event, the geographic collocation, the size and the antecedents, so that they lead to a specific evaluation for each underwriter. There are indeed circumstances in which the premium amount is less than $1,000 €$, but also others in which it exceeds $10,000 €$. Therefore, we believe that each single insurance contract, regardless of the event for which they intend to act, needs specific evaluations that differ in relation to the single Diocese's characteristics.

We also have to take into account the Dioceses that have not underwritten an insurance contract, specifically evaluating the motivations behind this decision.

Table 2. Motivations behind the non-underwriting

Source: Authors' own results.

\begin{tabular}{l|c}
\multicolumn{1}{c}{ Motivations } & Percentage, \% \\
\hline No resources & 26.09 \\
\hline No territory exposition & 21.74 \\
\hline No product knowledge & 13.04 \\
\hline $\begin{array}{l}\text { Available aid from the State in case of } \\
\text { Calamity }\end{array}$ & 13.04 \\
\hline No interest & 8.70 \\
\hline Under way & 8.70 \\
\hline No obligation & 4.35 \\
\hline No insurance culture & 4.35 \\
\hline
\end{tabular}

Table 2 shows that in $26.09 \%$ of the cases, the respondents have indicated that they do not have proper financial resources to underwrite an insurance contract. It is the motivation characterized by a higher percentage than any other choice, focusing the attention on the financial resources that each Diocese has that it can set aside for this kind of intervention. The percentage of answers corre- sponding to the motivation "I don't think that it is necessary to underwrite an insurance contract because the territory is not exposed towards natural calamity" is not so different (21.74\%). This result can be connected to the previous motivation, in a perspective in which, in relation to a not such a high perceived risk, they do not think that it is necessary to set aside a part of their own liquidity for this investment, because of a lack of funds or a well-pondered decision.

$13.04 \%$ of the non-insured affirms they do not know about the insured product and for this reason they have not provided for the underwriting. We find an equal percentage in the cases in which the insurance is not necessary, because respondents are convinced there is a first aid from the state in case of calamity. These two considerations indicate that for $26 \%$ of non-insured the lack of knowledge of the product and of its effective utility lead to not considering this solution. Therefore, it is possible that an awakening of the theme we are dealing with can positively influence the spread and the use of the insurance for the heritage the cathedrals represented. It is strongly desirable to promote these politics, to the extent that they can lead to a kind of prevention for events difficult to foresee. Especially for earthquakes, events that we are still not able to foresee, the only strategy being the adoption of prevention; and it is exactly in this field that insurance takes on importance.

\subsection{Results on perception and awareness}

The study now proceeds with an in-depth analysis of the evaluation of risk perception, taking into account both a current and a future prospective.

Regarding eventual previous events, 55.74\% of respondents affirm they have had experiences with phenomena of catastrophic nature of different entities and dimensions, while only $41.18 \%$ of this percentage has taken advantage of insurance coverage.

Based on the data collected, the analysis of the perception that the respondents have expressed about the future trend of the catastrophic events is particularly interesting. 


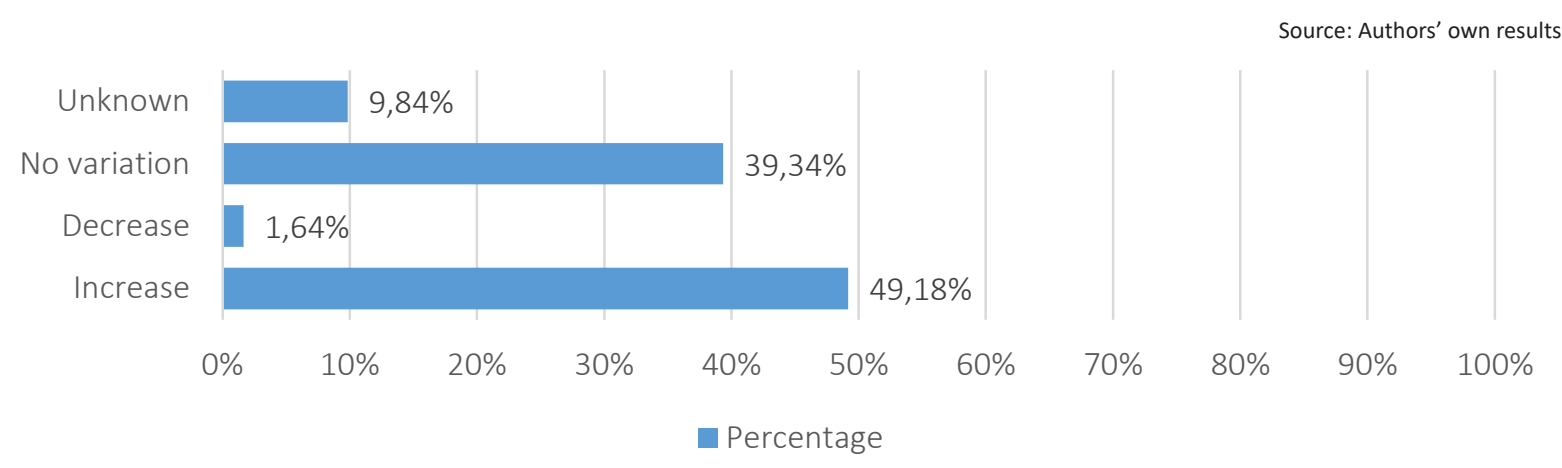

Figure 4. The future trend perception of catastrophic events

Figure 4 shows a graph in which it emerges that about the half of respondents argue that in the near future catastrophic events will increase. This consideration highlights a general state of apprehension towards these phenomena, strongly believing in an increase in the number of cases all throughout the national territory. It is a result that assumes great importance also in relation to the comparison that can be made between the perception of the future trend and the choice of being insured. What can be seen from this analysis is a strong relationship between these two variables, because in $76.67 \%$ of the cases, insures believe that an increase in the number of events can be observed, with a consequent increase of their own exposition. Compared to the perception of great danger, the Dioceses have decided to take out an insurance policy in order to protect and safeguard the historical, artistic and religious heritage the cathedrals represent.

After the evaluations made above, connected to the future trend of development and to the perception they have, the research now focuses on the awareness of their territory's current exposition. In other words, we are here considering whether or not the respondents are aware of the territorial vulnerability where their cathedrals are located. From the collected data emerges a medium perception of the risk. The majority of the answers, indeed, is around the medium value of the Likert scale $^{6}$ especially created to obtain some qualitative elements necessary for this evaluation.

By analyzing the last two elements in a univocal way, it is possible to argue that, if at the moment the perceived exposition of the territory is not so high, in the near future the scenario could change to one of greater dangerousness. The obtained answers show, indeed, that the evolution of the catastrophic events is going to lead the territory towards a greater exposition.

This awareness may originate from past experiences in the territory where the respondents live, but also from the past experience in other regions where the Diocese administrators lived. In the analyzed section, the emotional aspect, expressed as the sensitivity demonstrated towards these themes, assumes a central role and influences the answers obtained in a decisive way. There is no doubt that if they had lived through an event connected to natural disasters, there would be a greater participation and attention to the management of these phenomena. In this context, the mobility, that each Bishop has to follow to be head of the Dioceses, can be relevant. If they have witnessed occurrences connected to catastrophic events personally or attached great importance to the protection of the heritage they are asked to administrate, they could favor the spreading of a culture not only of simple prevention, but also of immediate reconstruction in case of damage, identifying insurance as a useful resource.

To this extent, an interesting reflection is suggested by the evaluation of the relationship between the insurance presence and the risk perception. In other words, we are here evaluating if and in which terms the awareness of one's own exposition to natural disasters can influence the willingness to underwrite insurance contracts.

6 The question is structured on 5 items, with a medium answer of 2.74 . 
From the collected data, emerges a substantial indifference between variables. In particular, through the estimation of an independence test, the Pearson's Chi-squared test, it gives a p-value equal to $0.9997^{7}$.

Chi-squared test for given probabilities

$X$-squared $=30.611, d f=60, p$-value $=0.9997$

This value leads to consider risk perception as a variable not sufficient enough to justify the willingness to underwrite a policy. This evaluation is strengthened by the percentage of insurance spread close to $60 \%$. If this were not true and the percentage of risk perception was the only variable that influenced the decisional process, then we could not justify a percentage of that value, but we should obtain one of a lower value, due to the different exposition of regions to catastrophic events.

Therefore, the obtained evaluation confirms the consideration according to which in the process of underwriting an insurance contract what comes into play are variables that go beyond a simple and detached analysis of the exposition of one's own territory. Sensitivity, emotiveness and eventual past experiences in other territories have a role of primary importance, jointly with the awareness of protecting a heritage of great significance not only in artistic terms, but also spiritual and liturgical ones, for the entire community. The religious aspect that characterizes all the cathedrals leads the ecclesiastic administrations to the research of a specific protection and it is exactly in this field that the insurance for the coverage of damages deriving from natural disasters is extremely preeminent.

These considerations find a huge corroboration in the data deriving from the request of clarification of the importance assumed by insurance. We have here obtained answers that highlight a relevant financial culture: the calculated mean shows a value equal to 4.02 , on a question structured with the technique of the Likert scale with 5 items: it is value that, in qualitative terms, can be translated as "medium/important".
Therefore, it is possible to affirm once again the sensibility shown by the Dioceses towards this solution. This evaluation confirms, as a consequence, the initial estimation concerning the insurance spread. The percentage of $62 \%$ could not be obtained if there were not recognition of the importance of insurance at the basis.

\subsection{Results on willingness to pay and future prospects}

The arguments here dealt with try to investigate, in a first analysis, scenarios of future trend in order to highlight which elements can improve the insurance spread.

The first variable here considered is linked to the presence of tax concessions and how they can encourage the underwriting of insurance contracts. We have asked participants to express clearly the importance an eventual introduction of this aid could have in the decisional process, trying to evaluate the efficacy. Also in this case, in order to obtain a quantitative evaluation of the answers, we have adopted the technique of the Likert scale with 5 items, as explained in the subsection 3.3. The obtained medium answer is equal to 3.95 . This value recognizes in tax concessions an element that can positively influence the choice of underwriting an insurance contract. Their eventual introduction can involve an increase in the number of underwriters, because they can benefit from a lower burden of taxation on the paid premium.

Another scenario is based on the possibility of underwriting a specific insurance contract, that is to say, defined on the peculiarity of their own territory, so that each contract differs from the others, being for all practical purposes an "unicum" in its sector.

In this case, the respondents recognize a similar relevance compared to the one obtained for the tax concessions, even though slightly lower (3.67 is the value of the average answer). As in the previous future prospective, we can identify an incentive to the underwriting of insurance contracts. An introduction of a similar measure from the insurance companies can increase the number of

$7 \quad$ With respect to a $p$-value greater than 0.5 , the test allows us to affirm the independence of the considered variables; if lower, there is dependence. 
Table 3. Willingness to pay

Source: Authors' own results.

\begin{tabular}{c|c|c|c|c|c:c}
\hline Classes & $\mathbf{0 - 1 , 0 0 0 €}$ & $\mathbf{1 , 0 0 0 - 2 , 0 0 0 €}$ & $\mathbf{2 , 0 0 0 - 3 , 0 0 0 €}$ & $\mathbf{3 , 0 0 0 - 4 , 0 0 0 €}$ & $\mathbf{4 , 0 0 0 - 5 , 0 0 0 €}$ & $\mathbf{>} \mathbf{5 , 0 0 0 €}$ \\
\hline Percentages & $26.32 \%$ & $28.07 \%$ & $15.79 \%$ & $3.51 \%$ & $17.54 \%$ & $8.77 \%$ \\
\hline
\end{tabular}

underwriters, allowing for a double benefit: insurance companies can benefit from a larger liquidity and the coverage of the artistic heritage can increase.

As a consequence of the data obtained, the adoption of similar measures in order to promote the recourse to insurance would be desirable. A policy of awareness, added to actions such as the ones prospected in this section, can improve a system that already today is a point of reference in the contrast to catastrophic events.

The last evaluation here reported involves the willingness to pay.

We evaluate at this point the possibility of the use of financial resources, with the allocation of a part of them for the payment of an insurance premium that offers coverage for damages deriving from natural disasters.

Table 3 shows the results obtained, subdivided into the categories indicated in the multiple-choice question to the Dioceses.

From an analysis of Table 3, a diversification of answers linked to the different characteristics of each Diocese emerges, taking into account above all their size and their available liquidity. In any case, we can deduce that more or less half of the respondents have indicated they are willing to pay an insured premium with its amount collocated in the first two categories. The remaining answers can be positioned in the other indicated premium classes, with a prevalence for the classes "2,000-3,000€" and "4,000-5,000", with a percentage equals to $33.33 \%$. The class " $>5,000 €$ " involves different answers: we can find out, indeed, values slightly greater than $5,000 €$, up to values of thousands of Euro more than $5000 €$.

Making a comparative analysis between these data and the ones regarding the motivations given for not underwriting, the picture that emerges is particularly interesting.

Table 4. Comparative analysis of motivations and willingness pay

Source: Authors' own results

\begin{tabular}{l|c}
\hline \multicolumn{1}{c}{ Motivations } & Willingness to pay \\
\hline No resources & $1,500 €$ \\
\hline No territory exposition & $1,100 €$ \\
\hline No product knowledge & $5,300 €$ \\
\hline $\begin{array}{l}\text { Available aid from the State in case } \\
\text { of calamity }\end{array}$ & $1,100 €$ \\
\hline No interest & $500 €$ \\
\hline Under way & $2,500 €$ \\
\hline No obligation & $4,500 €$ \\
\hline No insurance culture & $500 €$ \\
\hline
\end{tabular}

As analyzed in the subsection 4.1, one of the principal motivations for not underwriting an insurance policy is the lack of resources. To this extent, it emerges that if the Dioceses had greater available cash, they would allocate an insured premium with a medium amount of $1,500 €$, as emerges from Table 4 . This result attests once more the sensitivity that the Dioceses demonstrate towards the recourse to insurance, being willing to pay a premium of an important amount. The intervention scenarios for future trends of the sector, previously analyzed, assume here a great importance since they constitute some ways through which the number of underwriters could be increased, due to the predisposition demonstrated by the Dioceses. Continuing this comparative analysis, it emerges that in the case in which there is a low exposition to risk, the willingness to pay is equal to $1,100 €$. Seeing that the majority of answers can be identified in these two motivations, the consideration of a good predisposition of the Dioceses is even more reinforced.

Under some aspects, the willingness to pay demonstrated by the Dioceses that do not have insurance product knowledge is surprising. In this case, indeed, it emerges that the average amount they are willing to pay is greater than $5,000 €$. It is a particularly relevant amount in the light of the other answers obtained. This consideration leads 
us to reflect on the willingness of the Dioceses to protect their heritage and on the importance of appropriate information regarding all the possible solutions they can take advantage of.

An in-depth knowledge of insurance policies, together with a willingness to pay, can make a more efficient resolution to the problems deriving from natural disasters.

\section{CONCLUSION}

This article provides an in-depth analysis of the spread of insurance policies against natural disasters for Italian cathedrals. We have analyzed different aspects linked to the choice of being insured, studying different variables and making comparisons between them.

For the cases analyzed, it emerges that Italian Dioceses demonstrate a great sensitivity in dealing with these situations. This evaluation takes on importance above all when seen in comparison with the data connected to the coverage of private homes: $62 \%$ versus $2 \%$. It provides a great relief to the obtained results, identifying in the Italian Dioceses a benchmark to follow, for the coverage of the huge cultural, artistic and religious heritage in Italy.

In accordance with this remarkable result, the article outlines some elements that affect the decisional process and some future considerations, in the perspective of providing solutions that can establish an important strategy to efficiently contrast the damages deriving from natural disasters.

\section{REFERENCES}

1. Abraham, K. S. (1985). Efficiency and fairness in insurance risk classification. Virginia Law Review, 71(3), 403-451. http://dx.doi. org/10.2307/1072963

2. ANIA, Associazione Nazionale tra le Imprese Assicuratrici (2017). Italian insurance 2016-2017. Retrieved from www.ania.it/export/sites/default/it/pubblicazioni/ rapporti-annuali/Italian-Insurance-Statistical-appendix/ItalianInsurance/2016-2017/ITALIANINSURANCE-2016-17.pdf

3. Browne, M., \& Hoyt, R. (2000). The Demand for Flood Insurance: Empirical Evidence. Journal of Risk and Uncertainty, 20(3), 291-306. https://doi. org/10.1023/A:1007823631497

4. Chiabrando, F., Colucci, E., Lingua, A., Matrone, F., Noardo, F., \& Spanò, A. (2018). A European interoperable database (Eid) to increase resilience of cultural heritage. The International Archives of the Photogrammetry, Remote Sensing and Spatial Information Sciences, XLII-3/W4 (Geoinformation for Disaster
Management (Gi4DM), 18-21 March 2018, Istanbul, Turkey). Retrieved from https://www. int-arch-photogramm-remotesens-spatial-inf-sci.net/XLII3-W4/151/2018/isprs-archivesXLII-3-W4-151-2018.pdf

5. Council of Europe. Committee of Ministers, Recommendation No.R (93)9. (1993). Of the Committee Of Ministers To Member States On The Protection Of The Architectural Heritage Against Natural Disasters. Retrieved from https://rm.coe.int/ native/09000016804fd763

6. De Masi, F., \& Porrini, D. (2018). Vulnerability to Natural Disasters and Insurance: Insights from the Italian Case. International Journal of Financial Studies, 6(2), 56. https://doi.org/10.3390/ ijfs6020056

7. Gafni, A. (1998). Willingness to Pay. PharmacoEconomics, 14(5), 465-470. https:// doi.org/10.2165/00019053199814050-00001

8. Gizzi, F., \& Porrini, D. (2017) Policy Choice and Insurance
System for Catastrophic Risks: The Case of Cultural Heritage. Journal of Multidisciplinary Research, Spring, 9(1), 63-77.

9. Gizzi, F.T., Potenza, M. R., \& Zotta, C. (2016) The Insurance Market of Natural Hazards for Residential Properties in Italy. Open Journal of Earthquake Research, 5(1), 35-61. https://doi. org/10.4236/ojer.2016.51004

10. Guidoboni, E., \& Valensise, G. (2013). L'Italia dei Disastri: Dati e Riflessioni sull'impatto Degli Eventi Naturali, 1861-2013. Bologna: Bononia University Press. Retrieved from https://www. amazon.it/disastri-riflessionisullimpatto-naturali-1861-2013/ $\mathrm{dp} / 8873959040$

11. Harrington, S. E. (2000). Rethinking disaster policy. Regulation, 23(1), 40-46. Retrieved from https://object.cato.org/sites/cato. org/files/serials/files/regulation/2000/4/harrington.pdf

12. Holzheu, T., \& Turner, G. (2018). The Natural Catastrophe Protection Gap: Measurement, Root Causes and Ways of Addressing 
Underinsurance for Extreme Events. The Geneva Papers on Risk and Insurance - Issues and Practuce, 43(1), 37-71. https://doi. org/10.1057/s41288-017-0075-y

13. Hoy, M. (1982). Categorizing Risks in the Insurance Industry. Quarterly Journal of Economics, 97(2), 321-336. http://dx.doi. org/10.2307/1880761

14. Italian National Institute of Geophysics and Volcanology, April 2004. Retrieved from zonesismiche.mi.ingv.it/mappa_ps_apr04/ italia.html

15. Kunreuther, H. (1996). Mitigating Disaster Losses through Insurance. Journal of Risk and Uncertainty 12(2-3), 171-187. http://dx.doi. org/10.1007/BF00055792

16. Le Den, X., Persson, M., Benoist, A., Hudson, P., de Ruiter, M., de Ruig, L., \& Kuik, O. (2017). Insurance of weather and climate related disaster risk: Inventory and analysis of mechanisms to support damage prevention in the EU. Publications Office of the European Union. https://doi.org/10.2834/40222

17. Logue, K. D., \& Ben-Shahar, O. (2012). Outsourcing Regulation: How Insurance Reduces Moral Hazard. Michigan Law Review, 111(2). Retrieved from https:// repository.law.umich.edu/mlr/ vol111/iss $2 / 2$
18. Nelli, H. (1972). The Earliest Insurance Contract. A New Discovery. The Journal of Risk and Insurance, 39(2), 215-220. https:// doi.org/10.2307/251881

19. OECD (2010). Reviews of Risk Management Policies OECD Reviews of Risk Management Policies: Italy 2010. Review of the Italian National Civil Protection System.

20. Porrini, D. (2011). The (potential) role of insurance sector in climate change economic policies. Environmental Economics, 2(1), 28-37. Retrieved from http:// www.irbis-nbuv.gov.ua/cgi-bin/ irbis_nbuv/cgiirbis_64.exe?I21 $\mathrm{DBN}=\mathrm{LINK} \& \mathrm{P} 21 \mathrm{DBN}=\mathrm{UJRN}$ $\& Z 21 \mathrm{ID}=\& S 21 \mathrm{REF}=10 \& \mathrm{~S} 21 \mathrm{C}$ $\mathrm{NR}=20 \& \mathrm{~S} 21 \mathrm{STN}=1 \& \mathrm{~S} 21 \mathrm{FMT}$ $=$ ASP_meta $\&$ C $21 \mathrm{COM}=\mathrm{S} \& 2$ S21P03 $=$ FILA $=\& 2$ S21STR=envirecon_2011_2_1_5

21. Porrini, D., \& Schwarze, R. (2014). Insurance models and European climate change policies: an assessment. European Journal of Law and Economics, 38(1), 7-28. https://doi.org/10.1007/s10657012-9376-6

22. Priest, G. (1996). The government, the market, and the problem of catastrophic risk. Journal of Risk and Uncertainty, 12(2-3), 219-237. https://doi.org/10.1007/ BF00055795
23. Slovic, P. (1987). Perception of risk. Science, 236(4799), 280-285. https://doi.org/10.1126/science. 3563507

24. Spennemann, D. H. R., \& Graham, K. (2007). The importance of heritage preservation in natural disaster situations. International Journal of Risk Assessment and Management, 7(6/7), 993. https://doi. org/10.1504/ijram.2007.014670

25. Throsby, D. (2010). The economics of cultural policy (Cambridge Books). Cambridge, England: Cambridge University Press.

26. Wang, M., Liao, C., Yang, S., Zhao, W., Liu, M., \& Shi, P. (2012). Are People Willing to Buy Natural Disaster Insurance in China? Risk Awareness, Insurance Acceptance, and Willingness to Pay. Risk Analysis, 32(10), 1717-1740. https://doi.org/10.1111/j.15396924.2012.01797.x

27. Warner, K., Yuzva, K., Zissener, M., Gille, S., Voss, J., \& Wanczeck, S. (2013). Innovative insurance solutions for climate change: how to integrate climate risk insurance into a comprehensive climate risk management approach (Vol. 12). Bonn, Germany: UNU-EHS. Retrieved from http://www. climate-insurance.org/fileadmin/ mcii/documents/20131107MCIIGIZ_Innovative_Insurnce_Solutions_for_CC_web.pdf 